\title{
Pengembangan SSP Kimia Berbasis Pendidikan Berkelanjutan untuk Meningkatkan Literasi Kimia dan Kesadaran terhadap Lingkungan
}

\author{
Magfirah Perkasa $^{1}$ *, Nurfina Aznam ${ }^{2}$ \\ ${ }^{1}$ Program Studi Pendidikan Kimia STKIP Bima. Jalan Piere Tendean, Mpunda, Bima, Indonesia. \\ ${ }^{2}$ Jurusan Pendidikan Kimia Universitas Negeri Yogyakarta. Jalan Colombo No. 1, Karangmalang, \\ Yogyakarta 55281, Indonesia. \\ * Korespondensi Penulis. Email: magfirahperkasa@gmail.com
}

\begin{abstract}
Abstrak
Penelitian ini bertujuan untuk mengetahui pengembangan, kelayakan dan efektifitas SSP kimia berbasis pendidikan berkelanjutan untuk meningkatkan literasi kimia dan kesadaran terhadap lingkungan peserta didik SMA. Model pengembangan diadaptasi dari model Dick \& Carey dengan subjek coba produk pada peserta didik kelas X SMA Negeri 11 Yogyakarta. Instrumen pengumpulan data meliputi lembar validasi, tes literasi kimia berformat benar-salah beralasan, lembar penilaian diri dan lembar penilaian antar teman terkait kesadaran terhadap lingkungan. SSP kimia divalidasi secara kualitatif dan kuantitatif. Hasil penelitian menunjukkan bahwa: (1) SSP kimia berbasis pendidikan berkelanjutan yang dikembangkan memiliki karakteristik yang meliputi pengembangan melalui model experiential learning pada materi hidrokarbon dan indikator literasi kimia maupun kesadaran terhadap lingkungan diadaptasi dari framework PISA 2015; serta (2) SSP kimia yang dikembangkan layak digunakan dengan kategori sangat baik serta efektif untuk meningkatkan literasi kimia dan kesadaran terhadap lingkungan peserta didik SMA berdasarkan uji Kruskal-Wallis.
\end{abstract}

Kata Kunci: SSP, pendidikan berkelanjutan, experiential learning, literasi kimia, kesadaran terhadap lingkungan

\section{Developing a Chemistry Subject Specific Pedagogy Based on Sustainability Education to Enhance Chemical Literacy and Environmental Awareness}

\begin{abstract}
The study aims to reveal the developing, the appropriateness and the effectiveness of a chemistry subject specific pedagogy based on sustainability education to enhance chemical literacy and environmental awareness of senior high school students. Developing model adapted from Dick \& Carey and the trial of this research product was conducted at SMA Negeri 11 Yogyakarta grade $10^{\text {th }}$ students. The instruments for data collection included validation instrument, a true-false reasoning chemical literacy test, environmental awareness self assessment and peer assessment. The product was validated as qualitative and quatitative validation. The results of research shows: (1) the features of chemistry subject specific pedagogy based on sustainability education is using experiential learning was taught to hydrocarbons and the indicators for chemical literacy test and environmental awareness adapted from framework PISA 2015; and (2) the chemistry subject specific pedagogy based on sustainability education is valid to use with very good category and effective to enhance chemical literacy and environmental awareness based on Kruskal-Wallis test.
\end{abstract}

Keywords: subject specific pedagogy, sustainability education, experiential learning, chemical literacy, environmental awareness.

How to Cite: Perkasa, M., \& Aznam, N. (2016). Pengembangan SSP kimia berbasis pendidikan berkelanjutan untuk meningkatkan literasi kimia dan kesadaran terhadap lingkungan. Jurnal Inovasi Pendidikan IPA, 2(1), 4657. doi:http://dx.doi.org/10.21831/jipi.v2i1.10269

Permalink/DOI: http://dx.doi.org/10.21831/jipi.v2i1.10269 


\section{PENDAHULUAN}

Perkembangan ilmu pengetahuan, teknologi dan seni (IPTEKS) menuntut sumber daya manusia (SDM) yang melek sains, melek teknologi dan pengetahuan baru. Kebutuhan SDM ini juga mempengaruhi bidang pendidikan untuk ikut andil dalam menjawab tuntutan kebutuhan. Proses pembelajaran seharusnya dapat menjadi wadah yang tepat untuk mewujudkan harapan tersebut. Melek sains dan teknologi dalam pembelajaran sains merupakan capaian belajar yang lebih tinggi. Peserta didik yang melek sains dan teknologi mampu mengaplikasikan konsep pembelajaran sains yang diperoleh di sekolah ke dalam kehidupan sehari-hari, serta dapat menjadikan lingkungan sekitar sebagai sumber belajar.

Peserta didik yang memiliki literasi kimia diharapkan dapat mengaplikasikan konsep kimia untuk menjelaskan fenomena yang terjadi di sekitarnya secara ilmiah dan mengaplikasinya untuk mempermudah aktivitas yang dilakukannya. Peserta didik yang memiliki literasi kimia secara bijak mampu menyeimbangkan antara perkembangan ilmu pengetahuan dan implikasinya terhadap lingkungan agar tidak terjadi kerusakan dan pencemaran lingkungan akibat dari pemanfaatan zat kimia yang tidak tepat maupun limbah industri. Sikap peduli dan sadar terhadap lingkungan tercermin dalam pribadi peserta didik yang memiliki literasi kimia.

Literasi kimia pada peserta didik dapat diukur dengan level tertentu dan di beberapa negara telah disisipkan dalam kurikulum pendidikan (Shwartz et al., 2006; Soobard \& Rannikmae, 2011). Berdasarkan hasil Program for International Student Assessment (PISA) 2012 menunjukkan bahwa literasi sains yang dimiliki peserta didik di Indonesia masih di bawah rata-rata (Kemendikbud, 2013c, p.5; OECD, 2014, p.5). PISA merupakan sebuah survei internasional dengan selang tiga tahun yang bertujuan untuk mengevaluasi sistem pendidikan di seluruh dunia dengan menguji keterampilan dan pengetahuan peserta didik. Indikator seorang peserta didik dinyatakan memiliki literasi kimia apabila menunjukkan kompetensi, seperti; (1) mampu menjelaskan fenomena yang terjadi di alam sekitar secara ilmiah; (2) mengevaluasi dan merancang penyelidikan ilmiah; serta (3) membuktikan dan menginterpretasikan data secara ilmiah (OECD, 2013, p.7). Rendahnya literasi sains yang dimiliki peserta didik Indonesia, memunculkan pemikiran mengenai perlunya literasi sains disisipkan dalam kurikulum pendidikan di Indonesia.

Hasil survei PISA dikuatkan oleh hasil studi pendahuluan tentang literasi kimia dan kesadaran terhadap lingkungan yang dilakukan di sekolah di Kota Yogyakarta. Istilah literasi sains masih dianggap asing dan hampir tidak pernah dinilai dengan baik oleh pendidik kimia di Kota Yogyakarta. Sikap kesadaran peserta didik terhadap lingkungan juga tidak dinilai dengan baik oleh pendidik kimia. Kesadaran peserta didik terhadap lingkungan hanya dievaluasi secara lisan, ditanyakan dan tidak dilengkapi dengan instrumen penilaian yang standar. Peserta didik dinyatakan memiliki kesadaran terhadap lingkungan apabila memiliki kompetensi, seperti: (1) mengetahui dan sadar terhadap isu serta permasalahan lingkungan; (2) memiliki persepsi dan kepedulian terhadap isu maupun permasalahan lingkungan; serta (3) memiliki kepercayaan diri dalam menyelesaikan permasalahan lingkungan dan berkontribusi untuk keberlangsungan lingkungan hidup (OECD, 2013, p.39). Pentingnya dua aspek ini menjadikan landasan bagi United Nations dan United $\mathrm{Na}$ tions Educational, Scientific, and Cultural Organization (UNESCO) untuk merekomendasikan konsep pendidikan berkelanjutan sebagai salah satu solusi untuk menjawab urgensinya (UNESCO, 2002; p.4; United Nations, 1987). Pendidikan berkelanjutan mempertimbangkan tiga domain utama dalam implementasinya, yaitu lingkungan, ekonomi dan sosial masyarakat (United Nations, 1987; Kuhlman \& Farrington, 2010; Nicolette et al., 2013).

UNESCO merekomendasikan model dan strategi pembelajaran yang digunakan untuk pendidikan berkelanjutan dan terbukti dapat meningkatkan literasi kimia dan kesadaran peserta didik terhadap lingkungan, di antaranya experiential learning (Redman, 2013; Brundiers et al., 2010; Sipos et al., 2008; Evans \& Graff, 2012; Mehra \& Kaur, 2010), project based learning (Micangeli et al., 2014; Jollands \& Parthasarathy, 2013), story-telling, values education, inquiry learning, appropriate assessment, future problem-solving, learning outside the classroom, \& community problem solving (UNESCO, 2002, p.5). Model experiential learning memiliki beberapa tahapan siklus (Mannen, 2012; Kolb \& Kolb, 2005), meliputi: (1) concrete experience (pengalaman nyata); (2) reflective observation (pengamatan yang reflektif); (3) abstract conceptualization (konseptual- 
isasi yang abstrak); serta (4) active experimentation (eksperimen aktif).

Pendidik sebagai fasilitator harus mampu menyusun rencana pelaksanaan pembelajaran yang baik agar tujuan pembelajaran dapat tercapai dengan optimal. Pendidik harus memperhatikan karakteristik peserta didik sebagai audience dan penggunaan model yang tepat agar sesuai dengan karakteristik materi, sehingga tujuan pembelajaran dapat tercapai dengan optimal serta dapat meningkatkan daya serap peserta didik terhadap materi terkait. Perangkat pembelajaran seharusnya disusun oleh pendidik kimia dengan memperhatikan konsep dan melakukan analisis mendalam terkait karakteristik peserta didik, materi dan kesesuaian model pembelajaran. Perangkat seperti ini dikenal sebagai subject specific pedagogy (SSP) (pedagogi khusus materi). Subject specific pedagogy merupakan istilah yang lahir dari pedagogy content knowledge $(P C K)$. PCK merupakan salah satu komponen pengetahuan profesional bagi seorang pendidik dan pertama kali dikenalkan oleh Lee Shulman pada tahun 1986 (Chapoo et al., 2014; Vesterinen, 2012, p.7; Shulman, 1987).

Berdasarkan studi pendahuluan menunjukkan bahwa sebagian pendidik belum mampu menyusun perangkat pembelajaran sendiri dengan memperhatikan kesesuaian antara materi dengan model pembelajaran yang diterapkan serta mempertimbangkan karakteristik peserta didik. Materi memiliki karakteristik yang berbeda. Karakteristik peserta didik dan model pembelajaran juga perlu diperhatikan dalam penyusunan rencana pembelajaran untuk materi tertentu. Materi hidrokarbon memiliki kesesuaian dengan model experiential learning serta sangat berhubungan erat dengan kehidupan sehari-hari peserta didik. Oleh karena itu, untuk menyelesaikan masalah tersebut, perlu pengembangan subject specific pedagogy kimia berbasis pendidikan berkelanjutan melalui model experiential learning. Langkah ini bertujuan untuk meningkatkan literasi kimia dan kesadaran peserta didik terhadap lingkungan. SSP kimia diharapkan efektif untuk meningkatkan literasi kimia dan kesadaran peserta didik terhadap lingkungan.

Pendidikan berkelanjutan merupakan konsep pembelajaran yang memperhatikan keterkaitan aspek lingkungan, ekonomi dan sosial masyarakat sebagai satu kesatuan dalam proses pembelajaran. Pendidikan berkelanjutan dimplementasikan melalui model experiential learning sebagai salah satu model pembelajaran yang direkomendasikan oleh UNESCO untuk materi hidrokarbon. Model experiential learning merupakan proses belajar yang menjadikan pengalaman sebagai media belajar atau pembelajaran untuk memperoleh pengetahuan yang baru. Model experiential learning memiliki tahapan siklus yang memuat: (1) concrete experience (pengalaman nyata); (2) reflective observation (pengamatan yang reflektif); (3) abstract conceptualization (konseptualisasi yang abstrak); serta (4) active experimentation (eksperimen aktif).

SSP kimia berbasis pendidikan berkelanjutan berupaya mengajarkan, membelajarkan dan mentransfer materi kimia berbasis model experiential learning sebagai salah satu model pembelajaran yang direkomendasikan untuk pedagogi konsep sustainability. SSP kimia berbasis pendidikan berkelanjutan meliputi: RPP, LKS dan instrumen penilaian yang dikembangkan berbasis sintaks model experiential learning.

Literasi kimia merupakan kemampuan peserta didik dalam mengidentifikasi, menganalisis, dan mengolah konsep kimia untuk menyelesaikan masalahnya dalam kehidupan sehari-hari dan mengkomunikasikan setiap fenomena kimia yang terjadi di sekitarnya secara ilmiah. Kemampuan literasi kimia peserta didik diukur menggunakan tes literasi kimia yang berformat benar-salah beralasan dengan indikator yang diadaptasi dari aspek competencies pada draft science framework PISA 2015.

Kesadaran terhadap lingkungan merupakan kombinasi antara sikap, pengetahuan dan keterampilan peserta didik untuk menjaga kelestarian lingkungan, mencegah dari kerusakan dan memberikan alternatif solusi terkait dengan permasalahan lingkungan. Kesadaran peserta didik terhadap lingkungan diukur dengan menggunakan lembar penilaian diri dan lembar penilaian antar teman dengan indikator kesadaran terhadap lingkungan yang diadaptasi dari aspek attitudes pada draft science framework PISA 2015.

Penelitian yang relevan dengan penelitian ini, antara lain penelitian yang telah dilakukan oleh Noor \& Wilujeng (2015) yang mengembangkan SSP fisika berbasis pendekatan contextual teaching learning (CTL) untuk meningkatkan keterampilan proses sains dan motivasi belajar. Penelitian yang mengkaji mengenai pengaruh model experiential learning terhadap hasil belajar peserta didik SMA dilakukan oleh 
Julius \& Wachanga (2013) pada peserta didik kelas X salah satu SMA di Kenya.

Shwartz, Ben-Zvi \& Hofstein (2006) menggunakan taksonomi literasi sains untuk melakukan penelitian evaluasi tentang literasi kimia peserta didik kelas X sampai XII di Israel. Saxena \& Srivastava (2012) melakukan penelitian tentang kesadaran peserta didik terhadap lingkungan dan sikap ramah lingkungan (ecofriendly) pada peserta didik kelas XI. Penelitian tentang kesadaran terhadap lingkungan dan sikap peduli lingkungan juga dilakukan oleh Sengupta, Das, \& Maji (2010). Gender dan aliran (seni, sains dan komersial) menjadi variabel independen yang mempengaruhi kesadaran terhadap lingkungan dan sikap peduli lingkungan peserta didik.

\section{METODE}

Penelitian ini termasuk dalam kelompok penelitian pengembangan atau Research and Development $(R \& D)$. Model pengembangan yang digunakan, yaitu adaptasi dari model Dick \& Carey (Dick, Carey, \& Carey, 2001, p.13) yang diadaptasi menjadi lima langkah, yaitu: pendahuluan, analisis, perancangan, pengembangan, dan pengujian.

\section{Waktu dan Tempat Penelitian}

Penelitian dilakukan pada bulan November 2014-Mei 2015 yang terdiri dari studi pendahuluan pada bulan November 2014-Februari 2015, serta pengambilan data pada bulan MaretMei 2015. Studi pendahuluan dilakukan pada tiga sekolah, yaitu SMA Negeri 11 Yogyakarta, SMA Negeri 9 Yogyakarta dan MAN Maguwoharjo. Proses pengambilan data untuk uji coba produk dilakukan di SMA Negeri 11 Yogyakarta.

\section{Subjek Penelitian}

Subjek coba produk SSP kimia berbasis pendidikan berkelanjutan merupakan peserta didik kelas X SMA Negeri 11 Yogyakarta. Subjek uji coba terbatas meliputi 10 peserta didik kelas X-E. Subjek uji coba lapangan meliputi 28 peserta didik kelas X-F sebagai kelas eksperimen dan 28 peserta didik kelas X-D sebagai kelas kontrol. Desain uji coba pada penelitian ini termasuk dalam tipe nonequivalent control group design.

\section{Prosedur}

Prosedur pengembangan diadaptasi dari model pengembangan Dick \& Carey yang dimodifikasi menjadi lima langkah, yaitu pendahuluan, analisis, perancangan, pengembangan dan pengujian. Tahap pendahuluan dilakukan untuk mengetahui masalah dan kebutuhan pengguna (pendidik dan peserta didik) terhadap produk pengembangan, sehingga dapat digunakan sebagai data pendukung untuk memperkuat tujuan pengembangan produk. Studi pendahuluan dilakukan dengan wawancara dan observasi pada pendidik kimia dan peserta didik di sekolah. Studi literatur dilakukan untuk menindaklanjuti hasil yang diperoleh pada studi pendahuluan. Tahap analisis dilakukan untuk menganalisis lebih lanjut terkait komponen utama yang dibutuhkan dalam pengembangan SSP kimia, yaitu karakteristik peserta didik, konsep materi, kompetensi dasar dan indikator pada materi hidrokarbon.

Hasil studi pendahuluan dan analisis dijadikan sebagai dasar dalam tahap perancangan yang bertujuan untuk merancang draft produk pengembangan serta intrumen validasi produk. Sebanyak tiga komponen utama produk SSP kimia yang dikembangkan, yaitu RPP, LKS dan instrumen penilaian. RPP dikembangkan berdasarkan komponen yang tertuang dalam Permendikbud RI No. 65 Tahun 2013 Tentang Standar Proses Pendidikan Dasar dan Menengah (Kemendikbud, 2013b). LKS dikembangkan berdasarkan komponen yang diadaptasi dari Devi, Sofiraeni \& Khairuddin (2009). Komponen utama yang perlu diperhatikan dalam penyusunan LKS meliputi aspek penyajian materi dan aspek tampilan.

Instrumen penilaian literasi kimia disusun dengan format soal benar-salah beralasan dengan indikator penjabaran yang diadaptasi dari framework PISA 2015 aspek competencies. Kesadaran terhadap lingkungan diukur dengan menggunakan lembar penilaian diri dan lembar penilaian antar teman yang juga diadaptasi dari framework PISA 2015 aspek attitudes. Semua komponen draft produk dikembangkan lebih lanjut dan diperbaiki kualitasnya dengan tahapan validasi yang dilakukan secara kualitatif dan kuantitatif. Tahap akhir pengembangan berupa pengujian produk yang terdiri dari dua tahap, yaitu uji coba terbatas dan uji coba lapangan. Prosedur pengembangan diilustrasikan pada Gambar 1. 


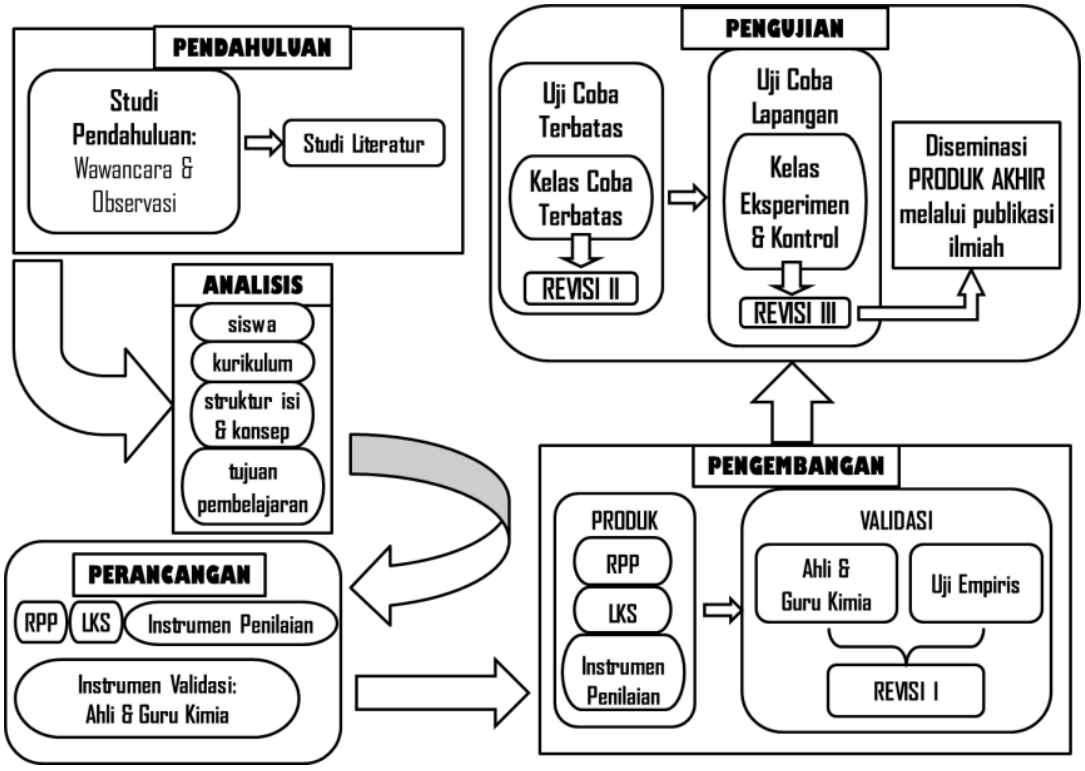

Gambar 1. Prosedur Pengembangan

\section{Data, Intrumen, dan Teknik Pengumpulan Data}

Kelayakan produk divalidasi logis oleh dosen ahli dan pendidik kimia menggunakan lembar validasi. Hasil validasi dianalisis secara kualitatif, serta diklasifikasikan dengan kategori sangat baik, baik, tidak baik dan sangat tidak baik. Tes literasi kimia juga divalidasi empiris menggunakan 30 peserta didik kelas XI IPA 1 SMA Negeri 11 Yogyakarta. Data literasi kimia dikumpulkan menggunakan 15 item tes literasi kimia berformat benar-salah beralasan. Data kesadaran lingkungan diperoleh dengan lembar penilaian diri dan lembar penilaian antar teman masing-masing sebanyak 12 item. Teknik dan instrumen pengumpulan data disajikan pada Tabel 1.

Tabel 1. Teknik dan Instrumen Pengumpulan Data

\begin{tabular}{ll}
\hline \multicolumn{1}{c}{ Jenis } & \multicolumn{1}{c}{ Instrumen } \\
Wawancara & Daftar Pertanyaan \\
Observasi & Lembar Observasi \\
& Keterlaksanaan RPP \\
Literasi Kimia & Tes Literasi Kimia \\
Kesadaran Terhadap & Lembar Penilaian Diri \\
Lingkungan & Lembar Penilaian Antar \\
& Teman \\
\hline
\end{tabular}

\section{Teknik Analisis Data}

Data hasil validasi logis oleh dosen ahli dan pendidik kimia dikonversi dalam skala empat (Mardapi, 2008, p.123) dengan pedoman konversi seperti disajikan pada Tabel 2.
Tabel 2. Konversi Skor Validasi Skala Empat

\begin{tabular}{ccc}
\hline No. & Kriteria Ketercapaian & Kategori \\
1. & $x \geq \bar{x}+1 . \mathrm{SBx}$ & Sangat Baik \\
2. & $\bar{x}+1 . \mathrm{SBx}>x \geq \bar{x}$ & Baik \\
3. & $\bar{x}>x \geq \bar{x}-1 . \mathrm{SBx}$ & Tidak Baik \\
4. & $x<\bar{x}-1 . \mathrm{SBx}$ & Sangat Tidak \\
\end{tabular}

(Mardapi, 2008, p.123)Hasil perhitungan skor validasi untuk masing-masing komponen produk digunakan untuk menyusun kategori kelayakan produk seperti disajikan pada Tabel 3.

Tabel 3. Kategori Kelayakan Produk Pengembangan

\begin{tabular}{|c|c|c|c|c|}
\hline \multicolumn{3}{|c|}{ Interval Komponen Produk } & \multirow{2}{*}{$\begin{array}{l}\text { Ni } \\
\text { lai }\end{array}$} & \multirow[b]{2}{*}{ Kategori } \\
\hline RPP & LKS & $\begin{array}{c}\text { Instrumen } \\
\text { Penilaian }\end{array}$ & & \\
\hline$x \geq 65,1$ & $x \geq 34,1$ & $x \geq 12,4$ & A & $\begin{array}{c}\text { Sangat } \\
\text { Baik }\end{array}$ \\
\hline $\begin{array}{c}65,1>x \\
\geq 52,5\end{array}$ & $\begin{array}{c}34,1>x \\
\geq 27,5\end{array}$ & $\begin{array}{c}12,4>x \geq \\
10\end{array}$ & $\mathrm{~B}$ & Baik \\
\hline $\begin{array}{c}52,5>x \\
\geq 39,9\end{array}$ & $\begin{array}{c}27,5>x \\
\geq 20,9\end{array}$ & $\begin{array}{c}10>x \geq \\
7,6\end{array}$ & $\mathrm{C}$ & $\begin{array}{l}\text { Tidak } \\
\text { Baik }\end{array}$ \\
\hline$x<39,9$ & $x<20,9$ & $x<7,6$ & $\mathrm{D}$ & $\begin{array}{c}\text { Sangat } \\
\text { Tidak } \\
\text { Baik }\end{array}$ \\
\hline
\end{tabular}

Keterlaksanaan pembelajaran kimia menggunakan RPP yang bersintaks model experiential learning dianalisis berdasarkan persentase keterlaksanaan dengan rumus $\mathrm{P}=$ $\frac{\mathrm{x}}{\mathrm{n}} \times 100 \%$. P menggambarkan persentase keterlaksanaan, $\mathrm{x}$ merupakan rata-rata skor dari dua observer, serta $n$ menggambarkan jumlah kegiatan pembelajaran yang disusun dalam RPP. Keterlaksanaan pembelajaran dikategorikan menja- 
di tinggi, sedang dan rendah seperti yang disajikan pada Tabel 4.

Tabel 4. Kategori Keterlaksanaan Pembelajaran

\begin{tabular}{ccc}
\hline No. & Kriteria Ketercapaian & Kategori \\
\hline 1. & $\geq 80 \%$ & Tinggi \\
2. & $65 \%-80 \%$ & Sedang \\
3. & $<65 \%$ & Rendah \\
\hline
\end{tabular}

(Arikunto, 2010, p.245)

Peningkatan literasi kimia yang dimiliki peserta didik dianalisis dengan menghitung skor perolehan (gain) dari pretest dan posttest. Persamaan yang digunakan untuk menghitung gain skor, yaitu:

$$
\text { Gain } \text { Skor }=\frac{\text { Skor Posttest }- \text { Skor Pretest }}{100-\text { Skor Pretest }}
$$

Gain skor dikategorikan dalam 3 kriteria, yaitu tinggi, sedang dan rendah seperti yang disajikan pada Tabel 5.

Tabel 5. Kategori Gain Skor

\begin{tabular}{ccc}
\hline No. & Kriteria Gain Skor & Kategori \\
1. & $\langle g\rangle \geq 0,7$ & Tinggi \\
2. & $0,7>\langle g\rangle \geq 0,3$ & Sedang \\
3. & $\langle g\rangle<0,3$ & Rendah \\
\hline
\end{tabular}

(Hake, 1998)

Kesadaran peserta didik terhadap lingkungan diukur dengan menggunakan lembar penilaian diri dan lembar penilaian antar teman. Hasil penilaian dikonversi menggunakan pedoman penilaian sikap (Kemendikbud, 2013a, p.41). Rumus untuk menghitung sikap kesadaran terhadap lingkungan didasarkan pada selisih skor akhir (skor penilaian diri x 2) ditambah dengan skor penilaian antar teman (skor penilaian antar teman x 1) dibagi dengan $3(2+1)$. Skor akhir dikonversi dalam bentuk kategori (sangat baik, baik, cukup dan kurang) sesuai kriteria yang disajikan pada Tabel 6 .

Tabel 6. Kategori Sikap Kesadaran Terhadap Lingkungan

\begin{tabular}{ccc}
\hline No. & Konversi Skor & Kategori \\
1. & $3,33<x<4,00$ & Sangat Baik \\
2. & $2,33<x \leq 3,33$ & Baik \\
3. & $1,33<x \leq 2,33$ & Cukup \\
4. & $x \leq 1,33$ & Kurang \\
\hline
\end{tabular}

(Kemendikbud, 2013a, p.39; Kemendikbud, 2014, p.23)

Keefektifan SSP kimia untuk meningkatkan literasi kimia dan kesadaran terhadap lingkungan dianalisis secara statistik menggunakan uji Kruskal-Wallis dengan bantuan program
SPSS 16. Keefektifan didasarkan pada gain skor literasi kimia dan kesadaran terhadap lingkungan peserta didik. Uji Kruskal-Wallis merupakan uji statistik nonparametrik yang tidak mempersyaratkan data bersistribusi normal dan homogen. Hipotesis uji Kruskal-Wallis untuk literasi kimia, yaitu:

$\mathrm{H}_{0}$ :tidak terdapat perbedaan yang signifikan antara literasi kimia peserta didik kelas eksperimen dan kelas kontrol.

H1 :terdapat perbedaan yang signifikan antara literasi kimia peserta didik pada kelas eksperimen dan kelas kontrol.

Hipotesis uji Kruskal-Wallis untuk kesadaran terhadap lingkungan, yaitu:

H0: tidak terdapat perbedaan yang signifikan antara kesadaran terhadap lingkungan peserta didik pada kelas eksperimen dan kelas kontrol.

H1: terdapat perbedaan yang signifikan antara kesadaran terhadap lingkungan peserta didik pada kelas eksperimen dan kelas kontrol.

Jika nilai sig lebih besar atau sama dengan 0,05 , maka $\mathrm{H}_{0}$ diterima. Penerimaan $\mathrm{H}_{0}$ menggambarkan bahwa tidak terdapat perbedaan yang signifikan antara kesadaran terhadap lingkungan peserta didik pada kelas eksperimen dan kelas kontrol.

\section{HASIL DAN PEMBAHASAN}

\section{Hasil Pengembangan}

SSP kimia berbasis pendidikan berkelanjutan yang dikembangkan memiliki karakteristik, yaitu berupa RPP, LKS dan instrumen penilaian untuk meningkatkan literasi kimia dan kesadaran terhadap lingkungan peserta didik SMA. Pendidikan berkelanjutan diimplementasikan melalui model experiential learning untuk materi hidrokarbon. RPP dan LKS disusun menggunakan sintaks model experiential larning yang dikombinasikan dengan scientific approach dengan empat tahap, yaitu concrete experience, reflective observation, abstract concepttualization, dan active experimentation. RPP dan LKS memuat serangkaian kegiatan pembelajaran yang dapat mengeksplorasi literasi kimia dan sikap kesadaran terhadap lingkungan peserta didik pada materi hidrokarbon. Tes literasi kimia dikembangkan berformat benar-salah beralasan dengan indikator yang diadaptasi dari aspek competencies pada draft science framework PISA 2015. Kesadaran terhadap lingkungan diukur menggunakan lembar penilaian diri dan 
penilaian antar teman dengan indikator yang diadaptasi dari aspek attitudes pada draft science framework PISA 2015.

Kelayakan produk SSP kimia berbasis pendidikan berkelanjutan ditentukan melalui validasi logis dan empiris. Validasi logis dilakukan oleh dosen ahli dan pendidik kimia dengan perolehan skor seperti disajikan pada Tabel 7.

Tabel 7. Skor Hasil Validasi Produk

\begin{tabular}{ccccc}
\hline & & \multicolumn{3}{c}{ Skor Penilaian Produk } \\
\cline { 3 - 5 } No. & Validator & RPP & LKS & $\begin{array}{c}\text { Instrumen } \\
\text { Penilaian }\end{array}$ \\
\hline 1. & Dosen 1 & 84 & 42 & 16 \\
2. & Dosen 2 & 60 & 31 & 12 \\
Rata-rata & $\mathbf{7 2}$ & $\mathbf{3 6 , 5}$ & $\mathbf{1 4}$ \\
1. $\quad$ Pendidik 1 & 84 & 44 & 16 \\
2. Pendidik 2 & 84 & 43 & 16 \\
Rata-rata & $\mathbf{8 4}$ & $\mathbf{4 3 , 5}$ & $\mathbf{1 6}$ \\
Skor Maksimal & $\mathbf{8 4}$ & $\mathbf{4 4}$ & $\mathbf{1 6}$ \\
Kategori & Sangat & Sangat & Sangat Baik \\
Kelayakan & Baik & Baik &
\end{tabular}

Berdasarkan hasil validasi oleh dosen ahli dan pendidik kimia, menunjukkan bahwa semua komponen SSP kimia berbasis pendidikan berkelanjutan memiliki kriteria kelayakan sangat baik. Hasil validasi ini juga didukung oleh data percentage of agreement (PoA) yang menyatakan tingkat kesepakatan dua atau lebih validator dalam memberikan penilaian. PoA dihitung dengan menggunakan rumus yaitu: Percentage agreement $=100 \% \times\left(1-\frac{\mathrm{A}-\mathrm{B}}{\mathrm{A}+\mathrm{B}}\right)$ (Borich, 1994, p.385). A merupakan perolehan skor dari validator 1, sedangkan B merupakan perolehan skor dari validator 2. Lembar validasi yang baik memiliki reliabilitas dan konsistensi yang baik sebagai pengumpul data validasi. Nilai PoA yang semakin besar atau mendekati $100 \%$ menunjukkan bahwa lembar validasi yang digunakan memiliki reliabilitas dan konsistensi yang tinggi, sehingga kesepakatan dua atau lebih validator diasumsikan sama. PoA dua validator dalam memberikan penilaian disajikan pada Tabel 8.

Tabel 8. Percentage of Agreement Validator

\begin{tabular}{cccc}
\hline \multirow{2}{*}{ No. } & \multirow{2}{*}{ Produk } & \multicolumn{2}{c}{$\begin{array}{c}\text { Nilai Percentage } \\
\text { of Agreement (\%) }\end{array}$} \\
\cline { 3 - 4 } & & Dosen & Pendidik Kimia \\
\hline 1. & RPP & 83,33 & 100 \\
2. & LKS & 84,93 & 98,85 \\
3. & Instrumen Penilaian & 85,71 & 100 \\
\hline
\end{tabular}

Hasil perhitungan PoA menunjukkan bahwa nilai PoA untuk semua komponen SSP kimia dari dosen ahli maupun pendidik kimia lebih dari $80 \%$. Hasil ini mengindikasikan bahwa lembar validasi yang digunakan memiliki reliabilitas dan konsistensi yang tinggi sebagai alat ukur untuk mengumpulkan data. Informasi lain yang diperoleh dari nilai percentage of agreement yang besar menggambarkan SSP kimia yang divalidasi menggunakan lembar validasi dinyatakan layak untuk digunakan.

Validasi empiris dilakukan untuk mengetahui kelayakan instrumen penilaian yang digunakan secara empiris atau nyata. Instrumen penilaian yang diuji empiris, yaitu intrumen penilaian literasi kimia. Uji empiris dilakukan pada peserta didik kelas XI IPA 1 SMA Negeri 11 Yogyakarta. Skor tes literasi kimia peserta didik dianalisis dengan menggunakan program Quest. Program Quest menganalisis data secara kuantitatif dengan meninjau aspek tingkat kesukaran (item difficulty) dan mempertimbangkan fit item terhadap model dalam program Quest. Item dinyatakan valid atau fit dengan model dalam program Quest apabila berada pada kisaran 0,77 sampai 1,30 berdasarkan informasi pada INFIT MNSQ. Instrumen tes yang baik berdasarkan teori respon butir apabila memiliki tingkat kesukaran (item difficulty) yang beragam dari kisaran $-\infty$ sampai $+\infty$. Hasil analisis item tes literasi kimia menunjukkan bahwa sebanyak 14 item dinyatakan fit 15 item yang diuji. Item yang tidak fit direvisi agar dapat digunakan dalam uji coba terbatas.

\section{Hasil Uji Coba Terbatas}

Uji coba terbatas dilakukan dengan mengujikan SSP kimia menggunakan jumlah subjek yang terbatas, yaitu 10 orang peserta didik SMA Negeri 11 Yogyakarta. Keterlaksanaan pembelajaran ditinjau dari pencapaian seluruh langkah yang telah tertuang dalam RPP. RPP kimia yang dikembangkan dirancang untuk 4 kali pertemuan. Setiap pertemuan diobservasi keterlaksanaan langkah pembelajaran model experiential learning oleh dua observer. Keterlaksanaan pembelajaran dianalisis dengan menghitung persentase langkah pembelajaran berdasarkan alokasi waktu untuk setiap pertemuan. Pembelajaran dengan nilai persentase keterlaksanaan lebih besar atau sama dengan $80 \%$ dikategorikan tinggi. Untuk itu implementasi langkah pembelajaran dapat dicapai dengan baik. Persentase keterlaksanaan pembelajaran untuk setiap pertemuan disajikan pada Tabel 9. 
Jurnal Inovasi Pendidikan IPA, 2 (1), 2016 - 53

Magfirah Perkasa, Nurfina Aznam

Tabel 9. Keterlaksanaan Pembelajaran Kelas Uji Coba Terbatas

\begin{tabular}{cccccc}
\hline $\begin{array}{c}\text { Pertemuan } \\
\text { Ke- }\end{array}$ & $\begin{array}{c}\text { Jumlah } \\
\text { Kegiatan }\end{array}$ & \multicolumn{2}{c}{ Skor Observer } & $\begin{array}{c}\text { Persentase Keterlaksanaan } \\
(\boldsymbol{\%})\end{array}$ & $\begin{array}{c}\text { Kategori } \\
\text { Keterlaksanaan }\end{array}$ \\
\cline { 3 - 4 } & 15 & 14 & 15 & 96,66 & Tinggi \\
2 & 15 & 13 & 13 & 86,66 & Tinggi \\
3 & 15 & 15 & 15 & 100,00 & Tinggi \\
4 & 15 & 15 & 15 & 100,00 & Tinggi \\
\hline
\end{tabular}

Peningkatan literasi kimia peserta didik ditentukan dengan menganalisis skor perolehan (gain skor). Berdasarkan hasil analisis literasi kimia peserta didik, terdapat 9 dari 10 orang peserta didik yang memiliki gain skor dengan kategori tinggi. Jumlah peserta didik berdasarkan gain skor literasi kimia pada kelas uji coba terbatas disajikan pada Gambar 2.

Skor sikap kesadaran terhadap lingkungan yang diperoleh dari lembar penilaian diri dan antar teman dihitung dengan menggunakan rumus penilaian sikap. Sikap kesadaran terhadap lingkungan dengan kategori sangat baik atau baik dikategorikan bahwa pembelajaran telah berhasil membentuk kesadaran lingkungan peserta didik. Sebanyak 3 dari 10 peserta didik memiliki kesadaran terhadap lingkungan sangat baik, sedangkan 7 peserta didik dengan kriteria baik. Distribusi peserta didik berdasarkan kategori sikap kesadaran terhadap lingkungan disajikan pada Gambar 3.

\section{Hasil Uji Coba Lapangan}

Uji coba lapangan dilakukan pada dua kelas, yaitu kelas X-D sebagai kelas kontrol dan kelas X-F sebagai kelas eksperimen di SMA Negeri 11 Yogyakarta tahun pelajaran 2014/ 2015. Jumlah sampel pada kelas kontrol sebanyak 28 peserta didik, sedangkan pada kelas eksperimen sebanyak 28 peserta didik. Keterlaksanaan pembelajaran dianalisis dengan menghitung persentase langkah pembelajaran yang dapat diimplementasikan berdasarkan alokasi waktu untuk setiap pertemuan. Pembelajaran yang memiliki persentase keterlaksanaan lebih dari atau sama dengan $80 \%$ dikategorikan tinggi yang menggambarkan bahwa setiap langkah pembelajaran dapat terealisasi dengan baik. Persentase keterlaksanaan pembelajaran disajikan pada Tabel 10.

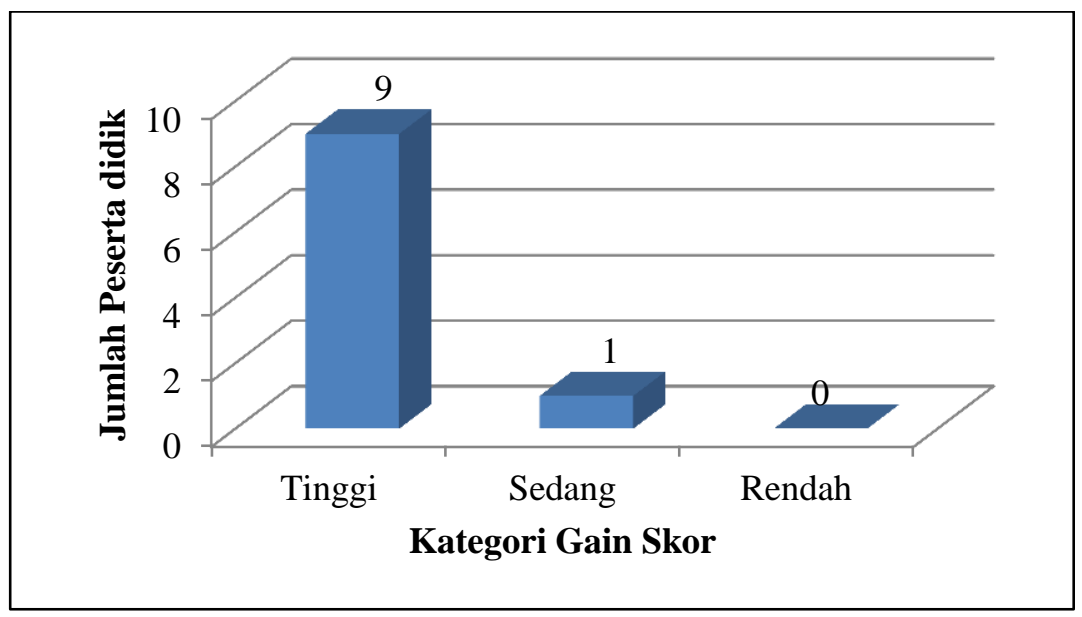

Gambar 2. Jumlah Peserta didik Berdasarkan Kategori Gain Skor Literasi Kimia 
Jurnal Inovasi Pendidikan IPA, 2 (1), 2016 - 54

Magfirah Perkasa, Nurfina Aznam

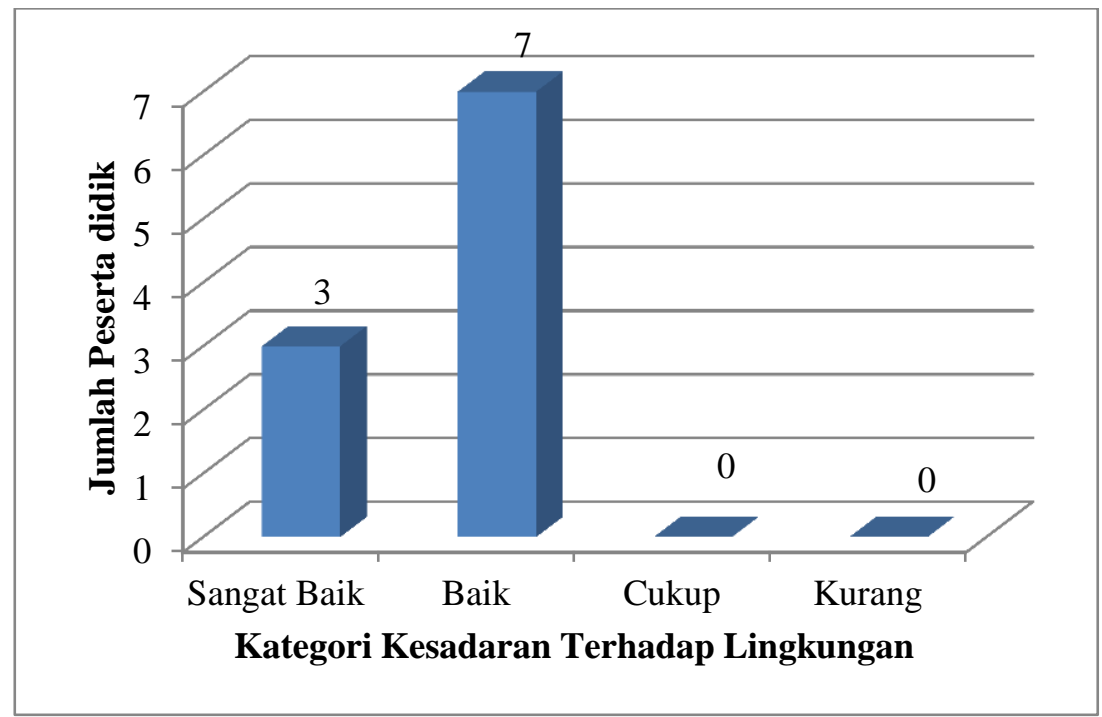

Gambar 3. Jumlah Peserta Didik Berdasarkan Kategori Sikap Kesadaran Terhadap Lingkungan

Tabel 10. Keterlaksanaan Pembelajaran Kelas Eksperimen

\begin{tabular}{|c|c|c|c|c|c|}
\hline \multirow{2}{*}{$\begin{array}{l}\text { Pertemuan } \\
\text { Ke- }\end{array}$} & \multirow{2}{*}{$\begin{array}{c}\text { Jumlah } \\
\text { Kegiatan }\end{array}$} & \multicolumn{2}{|c|}{ Skor Observer } & \multirow{2}{*}{$\begin{array}{c}\text { Persentase Keterlaksanaan } \\
(\%)\end{array}$} & \multirow{2}{*}{$\begin{array}{c}\text { Kategori } \\
\text { Keterlaksanaan }\end{array}$} \\
\hline & & $\mathbf{I}$ & II & & \\
\hline 1 & 15 & 15 & 15 & 100 & Tinggi \\
\hline 2 & 15 & 15 & 14 & 96,66 & Tinggi \\
\hline 3 & 15 & 14 & 15 & 96,66 & Tinggi \\
\hline 4 & 15 & 15 & 15 & 100 & Tinggi \\
\hline
\end{tabular}

Skor literasi kimia peserta didik untuk kelas eksperimen dan kelas kontrol diperoleh melalui tes literasi kimia dalam bentuk pretest dan posttest. Selisih antara skor pretest dan posttest menunjukkan besarnya gain skor. Gain skor digunakan untuk menentukan kategori peningkatan literasi kimia peserta didik. Jumlah peserta didik dengan gain skor tinggi pada kelas eksperimen lebih banyak dibandingkan yang terdapat pada kelas kontrol. Kategori peningkatan literasi kimia peserta didik yang dikelompokkan berdasarkan besarnya gain skor disajikan pada Tabel 11.

Tabel 11. Peningkatan Literasi Kimia Peserta Didik pada Uji Coba Lapangan

\begin{tabular}{lccc}
\hline No. & Kategori Gain & \multicolumn{2}{c}{ Jumlah Per Kategori } \\
\cline { 3 - 4 } & Skor & $\begin{array}{c}\text { Kelas } \\
\text { Eksperimen }\end{array}$ & $\begin{array}{c}\text { Kelas } \\
\text { Kontrol }\end{array}$ \\
\hline 1. & Tinggi & $\mathbf{1 8}$ & $\mathbf{9}$ \\
2. & Sedang & 10 & 12 \\
3. & Rendah & 0 & 7 \\
Jumlah Peserta didik & $\mathbf{2 8}$ & $\mathbf{2 8}$ \\
\hline
\end{tabular}

Kesadaran terhadap lingkungan peserta didik pada kelas eksperimen dan kelas kontrol diukur menggunakan lembar penilaian diri dan lembar penilaian antar teman. Lembar penilaian diri digunakan untuk mengukur pada kondisi awal (pretest) dan kondisi akhir (posttest). Penilaian antar teman hanya dilakukan setelah peserta didik mengikuti pembelajaran kimia materi hidrokarbon menggunakan model experiential learning. Penilaian antar teman tidak dilakukan pada kondisi awal pembelajaran, karena dikhawatirkan bersifat subjektif dan tidak akurat.

Jumlah peserta didik yang memiliki kesadaran terhadap lingkungan dengan kategori sangat baik lebih banyak ditemukan di kelas eksperimen dibandingkan di kelas control, yaitu di kelas eksperimen 10 peserta didik, sedangkan kelas kontrol hanya 1 peserta didik.

Tabel 12. Analisis Peningkatan Literasi Kimia Peserta didik pada Uji Coba Lapangan

\begin{tabular}{|c|c|c|c|}
\hline \multirow{2}{*}{ No. } & \multirow{2}{*}{$\begin{array}{l}\text { Kategori Kesadaran } \\
\text { Terhadap Lingkungan }\end{array}$} & \multicolumn{2}{|c|}{$\begin{array}{c}\text { Jumlah Per } \\
\text { Kategori }\end{array}$} \\
\hline & & $\begin{array}{c}\text { Kelas } \\
\text { Eksperimen }\end{array}$ & $\begin{array}{c}\text { Kelas } \\
\text { Kontrol }\end{array}$ \\
\hline 1. & Sangat Baik & 10 & 1 \\
\hline 2. & Baik & 18 & 27 \\
\hline 3. & Cukup & 0 & 0 \\
\hline 4. & Kurang & 0 & 0 \\
\hline & Jumlah Peserta didik & 28 & 28 \\
\hline
\end{tabular}

Hasil uji Kruskal-Wallis menunjukkan bahwa nilai sig untuk gain skor literasi kimia 
sebesar 0,001, sedangkan nilai sig untuk skor kesadaran terhadap lingkungan sebesar 0,000. Besarnya nilai sig untuk kedua variabel lebih kecil dari 0,05. Berdasarkan kriteria pengujian $\mathrm{H}_{0}$ dijelaskan bahwa nilai sig yang kurang dari 0,05 menggambarkan $\mathrm{H}_{0}$ ditolak. Penolakan $\mathrm{H}_{0}$ menggambarkan bahwa terdapat perbedaan yang signifikan antara literasi kimia dan kesadaran terhadap lingkungan peserta didik kelas eksperimen dan kelas kontrol.

Hasil penelitian menunjukkan bahwa SSP kimia berbasis pendidikan berkelanjutan efektif untuk meningkatkan literasi kimia dan kesadaran terhadap lingkungan peserta didik.

\section{SIMPULAN DAN SARAN}

\section{Simpulan}

Simpulan yang diperoleh dalam penelitian ini, yaitu: SSP kimia berbasis pendidikan berkelanjutan memiliki karakteristik di antaranya dikembangkan berbasis model experiential learning pada materi hidrokarbon dan indikator literasi kimia maupun kesadaran terhadap lingkungan diadaptasi dari framework PISA 2015; SSP kimia dengan kategori sangat baik, sehingga layak digunakan untuk pembelajaran kimia, serta SSP kimia efektif untuk meningkatkan literasi kimia dan kesadaran terhadap lingkungan peserta didik SMA.

\section{Saran}

SSP kimia sebaiknya digunakan untuk meningkatkan literasi kimia dan kesadaran terhadap lingkungan peserta didik kelas X SMA baik yang berlokasi dekat dengan pencemaran limbah plastik, polusi udara, maupun lokasi lainnya. Pendidik kimia dapat menerapkan model experiential learning untuk menambah pengalaman belajar yang nyata kepada peserta didik agar materi terkait dapat terserap dengan baik. Instrumen penilaian dapat digunakan untuk mendiagnosa kesulitan belajar dan miskonsepsi peserta didik pada materi hidrokarbon.

\section{DAFTAR PUSTAKA}

Arikunto, S. (2010). Dasar-dasar evaluasi pendidikan. Jakarta: Bumi Aksara.

Borich, G. D. (1994). Observation skills for effective teaching. New York: Macmillan Publishing Company.

Brundiers, K., Wiek, A., \& Redman, C. L. (2010). Real-world learning opportunities sustainability: From classroom into the real world. International Journal of Sustainability in Higher Education, 11(4), 308-324.

Chapoo, S., Thathong, K., \& Halim, L. (2014). Understanding Biology teachers'pedagogical content knowledge for teaching "the nature of organism". Procedia - Social and Behavioral Sciences, 116, $464-471$.

Devi, P. K., Sofiraeni, R., \& Khairuddin. (2009). Pengembangan perangkat pembelajaran. Bandung: PPPPTK IPA.

Dick, W., Carey, L., \& Carey, J. O. (2001). The systematic design of instruction (Fifth Edition ed.). Florida: Addison-Wesley Educational Publishers Inc.

Evans, J., \& Graff, E. (2012). Promoting environmental and cultural awareness through experiential learning. The International Journal of Sustainability Education, 1, 1-13.

Hake, R. R. (1998). Interactive-engagement vs traditional methods: a six-thousandstudent survey of mechanics test data for introductory physics courses. American Journal of Physics, 66(1), 64-74.

Jollands, M., \& Parthasarathy, R. (2013). Developing engineering students' understanding of sustainability using project based learning. Sustainability, 5, 5052-5066.

Julius, J. K., \& Wachanga, S. W. (2013). Effects of experiential concept mapping teaching strategy on students' achievement in chemistry in Imenti South District, Kenya. International Journal of Social Science \& Interdisciplinary Research, 2(8), 1-9.

Kemendikbud. (2013a). Model penilaian pencapaian kompetensi peserta didik sekolah menengah pertama. Jakarta: (Versi Elektronik).

Kemendikbud. (2013b). Peraturan Menteri Pendidikan dan Kebudayaan RI No. 65 
Tahun 2013 tentang Standar Proses Pendidikan Dasar dan Menengah.

Kemendikbud. (2013c). Peraturan Menteri Pendidikan dan Kebudayaan RI No. 70 Tahun 2013 tentang Kerangka Dasar dan Struktur Kurikulum Sekolah Menengah Kejuruan/Madarasah Aliyah Kejuruan.

Kemendikbud. (2014). Peraturan Menteri Pendidikan dan Kebudayaan RI No. 104 Tahun 2014 tentang Penilaian Hasil Belajar oleh Pendidik pada Pendidikan Dasar dan Pendidikan Menengah.

Kolb, A. Y., \& Kolb, D. A. (2005). Learning styles and learning spaces: Enhancing experiential learning in higher education. Academy of Management Learning \& Education, 4(2), 193-212.

Kuhlman, T., \& Farrington, J. (2010). What is sustainability? Sustainability, 2, 24363448 .

Mannen, K. (2012). Using experiential learning effectively. Pedagoggles: Exploring Teaching Practice, 3(8), 1-2.

Mardapi, D. (2008). Teknik penyusunan instrumen tes dan non tes. Yogyakarta: Mitra Cendikia.

Mehra, V., \& Kaur, J. (2010). Effect of experiential learning strategy on enhancement of environmental awareness among primary school students. Indian Educational Review, 47(2), 30-44.

Micangeli, A., Naso, V., \& Matrisciano, A. (2014). Attitudes toward sustainability and green economy issues related to some students learning their characteristics: A preliminary study. Sustainability, 6, 34843503.

Nicolette, J., Burr, S., \& Rockel, M. (2013). A practical approach for demonstrating environmental sustainability and stewardship through a net ecosystem service analysis. Sustainability, 5, 21522177.
Noor, F. M., \& Wilujeng, I. (2015). Pengembangan SSP fisika berbasis pendekatan CTL untuk meningkatkan keterampilan proses sains dan motivasi belajar. Jurnal Inovasi Pendidikan IPA, 1(1), 73-85.

OECD. (2013). PISA 2015: Draft science framework. New York: OECD Printing Office.

OECD. (2014). PISA 2012 results: What 15year-olds know and what they can do with what they know. Paris: OECD Printing Office.

Redman, E. (2013). Advancing Educational Pedagogy for Sustainability: Developing and Implementing Programs to Transform Behaviors. International Journal of Environmental \& Science Education, 8(1), 1-34.

Saxena, P., \& Srivastava, P. (2012). Environmental awareness of senior secondary students in relation to their ecofriendly behaviour. Research Scapes, I(II), 1-8.

Sengupta, M., Das, J., \& Maji, P. K. (2010). Environmental awareness and environment related behaviour of twelfth grade students in Kolkata: Effects of stream and gender. Anwesa, 5, 1-8.

Shulman, L. S. (1987). Knowledge and teaching: Foundations of the new reforms. Harvard Educational Review, 57(1), 1-21.

Shwartz, Y., Ben-Zvi, R., \& Hofstein, A. (2006). The use of scientific literacy taxonomy for assessing the development of chemical literacy among high-school students. Chemistry Education Research and Practice, 7(4), 203-225.

Sipos, Y., Battisti, B., \& Grimm, K. (2008). Achieving transformative sustainability learning: Engaging head, hands and heart. International Journal of Sustainability in Higher Education, 9(1), 68-86. 
Jurnal Inovasi Pendidikan IPA, 2 (1), 2016 - 57

Magfirah Perkasa, Nurfina Aznam

Soobard, R., \& Rannikmae, M. (2011). Assessing student's level of scientific literacy using interdisciplinary scenarios. Science Education International, 22(2), 133-144.

UNESCO. (2002). Teaching and learning for a sustainable future. Australia: Griffith University Publisher.
United Nations. (1987). Report of the world commission on environment and development: Our common future. New York.

Vesterinen, V.-M. (2012). Nature of science for chemistry: design of chemistry teacher education course. Disertasi Doktor, tidak diterbitkan, University of Helsinki, Helsinki. 